\title{
NGHIÊN CỨU CƠ SỞ KHOA HỌC XÂY DỰNG BỘ QUY TẮC HIỂN THỊ TỬ ĐộNG PHỤC VỤ THÀNH LẬP BẢN ĐỒ ĐỊA HİNH QUÂN SỬ TƯ CƠ SỞ DŨ LIỆU NỀN ĐỊA LÝ QUÂN SỰ
}

\author{
ThS. NGUYẼ̃N THI! LAN PHU'O'NG \\ Cục Bản đồ/BTTM
}

\section{Tóm tắt:}

Bài báo giơoi thiệu tóm tắt kết quả nghiên cứu xây dựng Bộ quy tắc hiển thị phục vụ thành lập bản đồ địa hình quân sự từ cơ sở dữ liệu (CSDL) nền địa lý quân sự, trên cơ sở ứng dụng công nghệ GIS và bản đồ số. Bộ quy tắc hiển thị được xây dựng là một phần của giải pháp nâng cao khả năng tự động hóa trong thành lập bản đồ từ CSDL. Các kết quả nghiên cứu hoàn toàn có thể áp dụng để xây dụng các Bộ quy tắc hiển thị cho bản đồ khác nhau tương ứng với từng mục đích sử dụng cụ thể.

\section{1. Đặt vấn đề}

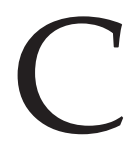
ùng với sự phát triển không ngừng của khoa học công nghệ, xu hướng cơ bản trong lĩnh vực đo đạc bản đồ hiện nay trên thế giới là thành lập các sản phẩm bản đồ nói chung, bản đồ địa hình nói riêng từ CSDL [8], [9]. Sự phát triển của khoa học kỹ thuật thành lập bản đồ theo công nghệ GIS đòi hỏi phải song hành với sự phát triển của tư duy cộng đồng trong thành lập và khai thác thông tin bản đồ. Tuy nhiên, việc thành lập bản đồ phụ thuộc phần lớn vào quan điểm trình bày của mỗi quốc gia, mỗi chuyên ngành nên không thể có sẵn một giải pháp chung.

Thực tế, việc trình bày và biên tập bản đồ theo quan điểm mô hình hóa gắn với các giải pháp tự động trong những năm gần đây đã thu hút được sự quan tâm sâu sắc của các nhà bản đồ học. Trong đó, đối tượng nghiên cứu tập trung vào các giải pháp tự động hóa phục vụ trình bày bản đồ theo hệ thống ký hiệu quy ước. Bộ quy tắc hiển thị tự động có thể hiểu là sự kết hợp giữa Bộ ký hiệu số gắn với các quy tắc hiển thị tự động phục vụ thành lập một loại bản đồ nhất định. Vì vậy, nghiên cứu xây dựng Bộ quy tắc hiển thị sẽ góp phần nâng cao khả năng tự động hóa thành lập bản đồ địa hình quân sự từ CSDL theo công nghệ ArcGIS.

\section{Giải quyết vấn đề}

2.1. Cơ sở lý thuyết, công nghệ xây dựng Bộ quy tắc hiển thị tự động

2.1.1. Phân tích khả năng trình bày bản đồ địa hình quân sự từ CSDL nền địa lý quân sự

Khái niệm trình bày bản đồ theo quan điểm truyền thống có thể coi là tương đương với khái niệm hiển thị thông tin địa lý dưới dạng các mô hình bản đồ khác nhau. Do đó, trong các thuật ngữ sử dụng sẽ đồng nhất khái niệm "hiển thị" thay cho khái niệm "trình bày".

Đối với bản đồ địa hình quân sự, yêu cầu về nội dung biểu thị bao gồm [2]: dáng đất, hệ thống thủy văn, thực phủ, thổ nhưỡng, vùng dân cư, mức độ phát triển kinh tế-văn

Người phản biện: TS. Đồng Thị Bích Phương 
hóa-xã hội, địa giới, điểm khống chế trắc địa và các công trình quân sự. Trong đó, các công trình quân sự là một nội dung quan trọng nhất của bản đồ địa hình quân sự. Thông tin này có thể hiển thị toàn bộ, hiển thị một phần hoặc không được phép hiển thị trên các bản đồ phụ thuộc vào yêu cầu bảo mật.

Đối tượng địa lý được định nghĩa như sau [7]: "Đối tượng địa lý (Feature) là mô tả một sự vật, hiện tượng trong thế giới thực (đường giao thông, sông, lượng mưa trong năm,...) có liên quan trực tiếp hoặc gián tiếp đến một vị trí địa lý hoặc mô tả một đối tượng không tồn tại trong thế giơoi thực nhưng cần thiết cho các mục đích sử dụng cu thể (địa giới hành chính, ranh giới thửa đất,...)". Với cách định nghĩa này khái niệm "đối tượng địa lý" bao trùm lên khái niệm "đối tượng bản đồ". Vì vậy, thông tin trong CSDL nền địa lý quân sự đủ cơ sở sử dụng để hiển thị bản đồ địa hình quân sự.

2.1.2. Một số thuật toán ứng dụng trong xây dựng Bộ quy tắc hiển thị

(1) Tìm kiếm một phần tử trong một tập hữu hạn các phần tử

Xác định vị trí của một phần tử trong một tập hữu hạn các phần tử. Thuật toán tìm kiếm tổng quát được mô tả như sau [5]: xác định vị trí của phần tử $x$ trong một dãy các phần tử $\mathrm{a} 1, \mathrm{a} 2, \ldots$, an hoặc xác định rằng nó không có mặt trong dãy. Input: dãy số a1, a2, ..., an và giá trị $x$; Output: Nghiệm là $i$ nếu $x=a i$ và là 0 nếu $x$ không có mặt trong dãy.

Thuật toán này có thể áp dụng cho việc chiết tách các thông tin địa lý là đối tượng bản đồ với quan hệ ánh xạ một-một (một đối tượng địa lý tương đương là một đối tượng bản đồ). Ví dụ: thuật toán chiết tách thông tin điểm tọa độ Nhà nước trong lớp điểm cơ sở quốc gia là: "doiTuong = 1", trong đó "doiTuong" là tập hợp các giá trị cho phép của một thuộc tính đối tượng địa lý
DiemCoSoQuocGia, có các giá trị từ 1 đến 3 tương ứng với các điểm tọa độ Nhà nước, điểm độ cao Nhà nước và điểm thiên văn.

\section{(2) Tìm kiếm tuyến tính}

Tìm kiếm tuyến tính hay tìm kiếm tuần tự. Tư tưởng thuật toán [5] là bắt đầu bằng việc so sánh $x$ với $a 1$; khi $x=a 1$, nghiệm là vị trí $a 1$, tức là 1 ; khi $x \neq a 1$, so sánh $x$ với a2. Nếu $\mathrm{x}=\mathrm{a} 2$, nghiệm là vị trí của $\mathrm{a} 2$, tức là 2 . Khi $x \neq a 2$, so sánh $x$ với a3. Tiếp tục quá trình này bằng cách tuần tự so sánh $x$ với mỗi số hạng của dãy cho tới khi tìm được số hạng bằng $\mathrm{x}$ hoặc là kết thúc dãy.

Thuật toán có thể áp dụng cho việc chiết tách thông tin địa lý là đối tượng bản đồ với quan hệ ánh xạ nhiều-một (nhiều đối tượng địa lý được biểu thị là một đối tượng bản đồ). Ví dụ: thuật toán chiết tách thông tin đường bình độ cái từ lớp DuongBinhDo như sau: "loaiDuongBinhDo = 1 AND loaiKhoangCaoDeu $=2$ AND $\bmod (\mathrm{doCaoH}, 10)=0 "$ trong đó "mod $(\mathrm{doCaoH}, 10)=0 "$ là cơ sở để so sánh giá trị các đường bình độ với mức cao thay đổi tuần tự tăng dần $10 \mathrm{~m}$, bắt đầu từ giá trị 0 cho đến hết.

\section{(3) Tìm kiếm nhị phân}

Thuật toán này có thể được dùng khi dãy số được sắp xếp đơn điệu theo thứ tự tăng hoặc giảm dần. Tư tưởng thuật toán [5] là chọn phần tử ở vị trí giữa làm chốt, chia dãy thành 2 phần có kích thước nhỏ hơn. Sau đó so sánh phần tử cần tìm $x$ với chốt, nếu $x$ lớn hơn chốt tìm ở nửa sau của dãy, nếu $x$ nhỏ hơn chỗ tìm ở nửa trước của dãy (áp dụng với dãy tăng), quá trình trên tiếp tục cho tới khi tìm được $x$ hoặc dãy chia không còn phần tử nào.

Thuật toán này có thể áp dụng cho việc chiết tách thông tin địa lý là đối tượng bản đồ với quan hệ ánh xạ nhiều-nhiều (một đối tượng địa lý được biểu thị thành nhiều đối tượng bản đồ). Ví dụ: thuật toán chiết tách 
thông tin hiển thị đối tượng Cây công nghiệp, cây ăn quả lâu năm từ lớp Phủ bề mặt chia thành hai trường hợp để biểu thị ký hiệu trải mảng tuyến tính hoặc lấy tâm hình học của đối tượng làm mốc trải đều ra xung quanh (khi diện tích vùng quá nhỏ vẫn được đặt ký hiệu tượng trưng) tương ứng như sau:

"doiTuong $=7$ AND loaiPhuBeMat $=2$ AND Shape_Area >=10000"

"doiTuong $=7$ AND loaiPhuBeMat $=2$ AND Shape_Area < 10000"

Trong đó chốt "Shape_Area" có giá trị "10000" được dùng để chia dãy số thành hai phần nhỏ hơn phục vụ chiết tách thông tin.

\subsubsection{Công nghệ ARCGIS}

Theo cách thức truyền thống, ký hiệu hóa chỉ là việc vận dụng Bộ ký hiệu số chính xác theo tọa độ không gian các đối tượng địa lý. Khi muốn biên tập phục vụ chế in hoặc hiển thị bản đồ số theo từng tỷ lệ phải xê dịch vị trí ký hiệu nhằm tránh xung đột không gian (đồng nghĩa với việc thay đổi tọa độ của dữ liệu gốc) [3], [4].

Công nghệ GIS (hay hệ thông tin địa lý) là một hệ thống bao gồm các thành phần: máy tính và các thiết bị ngoại vi; một CSDL chứa các thông tin không gian và các thông tin thuộc tính; một phần mềm có chứa các chức năng nhập thông tin không gian, tổ chức, lưu trữ, cập nhật, phân tích biến đổi thông tin và hiển thị thông tin dưới các dạng khác nhau. Công nghệ này cho phép thực hiện hoàn chỉnh quy trình công việc từ xây dựng CSDL địa lý cho đến mô hình hóa bản đồ hiển thị trên các máy tính và xuất bản bản đồ ra các phương tiện khác nhau. Dẫn đầu trong lĩnh vực công nghệ GIS về xây dựng CSDL và thành lập bản đồ hiện nay là ARCGIS V10.1 với modul Production Mapping, đã cho phép thiết lập trước các quy tắc hiển thị tự động ký hiệu đại diện (hay còn gọi là Luật hiển thị) cho mỗi loại đối tượng bản đồ, đồng thời không làm ảnh hưởng đến độ chính xác của dữ liệu gốc. Bộ phần mềm này chính là cơ sở để xây dựng tập hợp các quy tắc hiển thị bản đồ theo hướng tự động hóa.

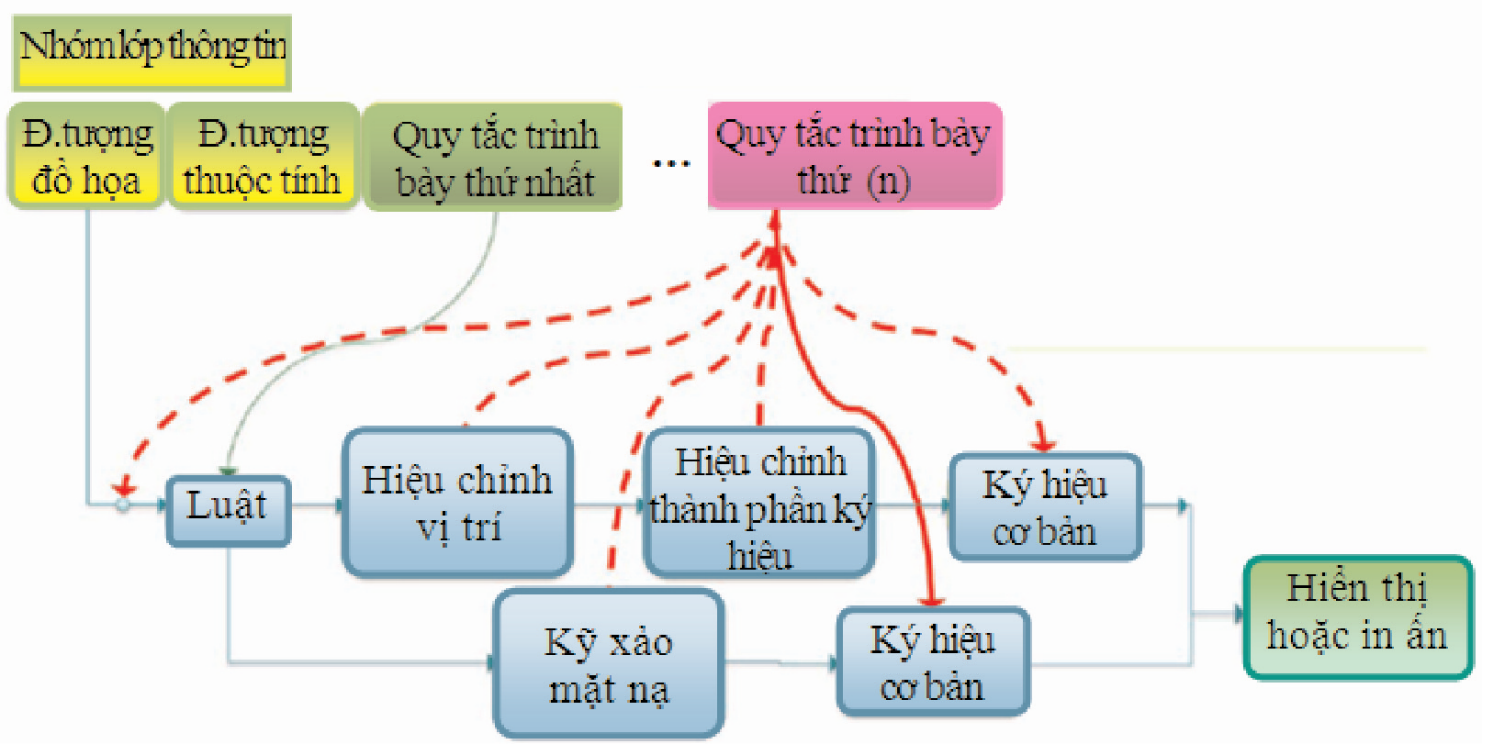

Hình 1: Minh họa nguyên tắc trình bày bản đồ theo công nghệ ARCGIS [6] 


\subsection{Nguyên tắc xây dựng Bộ quy tắc hiển thị tự động}

\subsubsection{Mô hình hiển thị bản đồ}

Sự phát triển của công nghệ GIS trong thành lập bản đồ dẫn đến yêu cầu về thống nhất một số khái niệm mới như sau [1]:

- Quy tắc hiển thị đối tượng địa lý: là các quy tắc được áp dụng cho một kiểu đối tượng địa lý trong lược đồ ứng dụng để chỉ ra các cách thức thể hiện kiểu đối tượng địa lý đó dưới dạng đồ họa.

- Danh mục hiển thị đối tượng địa lý: là một tập hợp các quy tắc hiển thị đối tượng địa lý.

- Chỉ thị hiển thị: là một tập hợp các thao tác hiển thị cần thiết phù hợp với mỗi quy tắc hiển thị cụ thể.

- Thao tác hiển thị: là cách thức được áp dụng để xử lý việc hiển thị dữ liệu địa lý cho một trường hợp cụ thể.

- Dịch vụ hiển thị: là các thao tác hiển thị cụ thể đối với dữ liệu địa lý.

Từ các khái niệm mới, theo quan điểm mô hình hóa bản đồ từ thông tin địa lý, có thể đề xuất các mô hình lý thuyết có liên quan đến hiển thị bản đồ bao gồm:

- Mô hình khái hiển thị bản đồ bao gồm các mô hình khái niệm Chỉ thị hiển thị, mô hình Danh mục hiển thị và mô hình Dịch vụ hiển thị phục vụ hiển thị hóa mô hình bản đồ từ mô hình CSDL nền địa lý. (Xem hình 2)

- Mô hình khái niệm Chỉ thị thị hiển thị dùng để định nghĩa khái niệm về một tập hợp các thao tác trình bày cần thiết phù hợp với mỗi quy tắc trình bày cụ thể. (Xem hình 3)

- Mô hình khái niệm Danh mục hiển thị để định nghĩa khái niệm về một tập hợp các quy tắc trình bày đối tượng địa lý. (Xem hình 4)

- Mô hình Dịch vụ hiển thị dùng để định nghĩa các thao tác trình bày cụ thể đối với dữ liệu địa lý.

- Dịch vụ trình bày là các thao tác trình bày cụ thể đối với dữ liệu địa lý. Các đối tượng địa lý được chiết tách từ CSDL và gán cho một ký hiệu hiển thị đại diện. Cách thức hiển thị vị trí của ký hiệu này có thể linh hoạt thay đổi mà không làm ảnh hưởng đến vị trí của dữ liệu vector gốc và có thể được định nghĩa trước bằng các quy tắc trình bày.

Tập hợp tất cả các quy tắc trình bày theo một hoặc nhiều mục đích khác nhau tạo thành các Bộ quy tắc trình bày cho từng loại sản phẩm.

\subsubsection{Xây dựng quy tắc hiển thị}

Quy tắc hiển thị đối tượng bản đồ từ thông tin địa lý là quy tắc được áp dụng cho một kiểu đối tượng địa lý trong lược đồ ứng dụng để chỉ ra các cách thức thể hiện kiểu đối tượng địa lý đó dưới dạng đồ họa. Để hiển thị hóa bản đồ theo hướng tự động hóa cần xây dựng các nguyên tắc phù hợp với tính năng tự động hóa hiển thị của phần mềm. Các nguyên tắc đề xuất bao gồm:

- Nguyên tắc duy nhất: mỗi đối tượng bản đồ có một tên gọi và một ký hiệu đại diện duy nhất.

- Nguyên tắc biểu thị chính xác vị trí đối tượng theo tâm hình học ký hiệu: ký hiệu có dạng hình học cơ bản (tâm hình học), ký hiệu tượng hình có đường đáy (tâm đường đáy), ký hiệu có chân vuông góc (góc vuông của chân), chấm tròn (tâm chấm tròn), vòng tròn ở chân (tâm vòng tròn), ký hiệu rỗng chân (tâm giữa hai chân), ký hiệu hình tuyến (trục giữa ký hiệu).

- Nguyên dịch vị trí tránh chồng đè, nhưng không quá $0,2 \times M$, đơn vị tính là mét, M là mẫu số tỷ lệ bản đồ cho đối tượng dạng điểm, và tính theo mép ký hiệu đối với đối tượng dạng đường; Đối tượng cùng mầu không được phép chồng đè lên nhau; Đối tượng dạng nét cắt phần đè qua chữ ghi 


\section{Nghiên cúu}

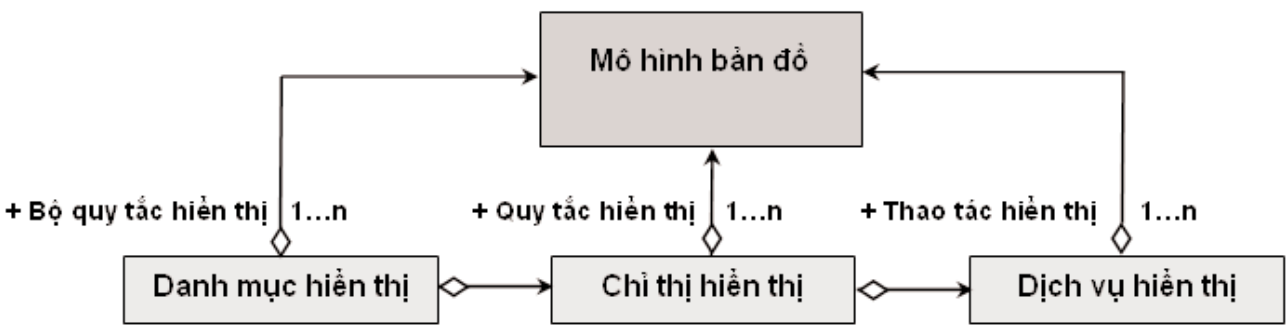

Hình 2: Mô hình khái niệm hiển thị bản đồ

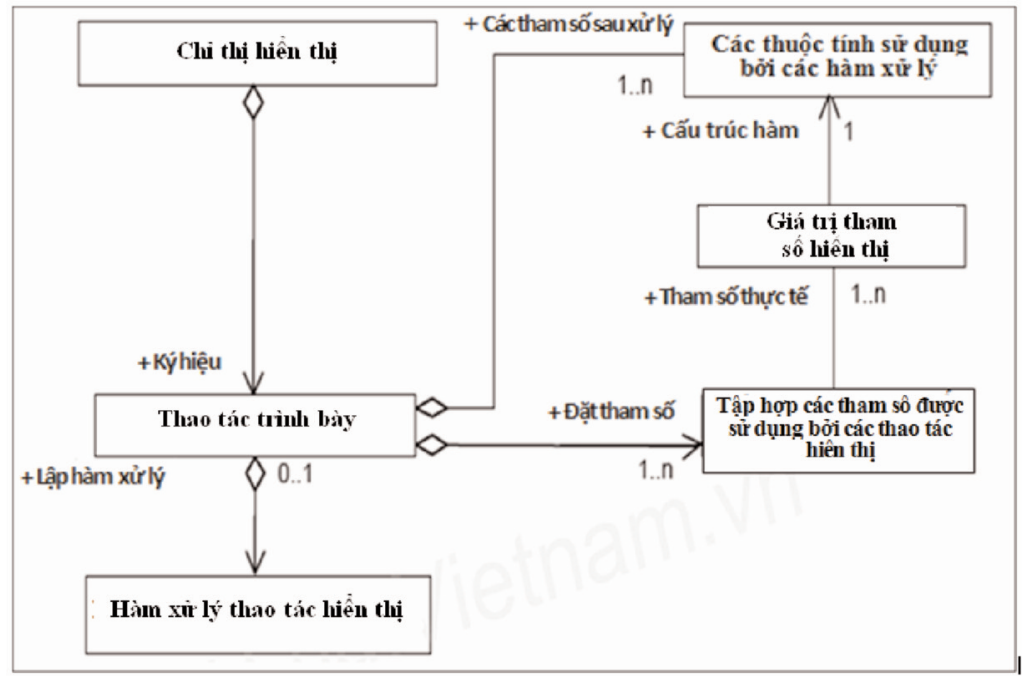

Hình 3: Mô hình khái niệm Chỉ thị hiển thị

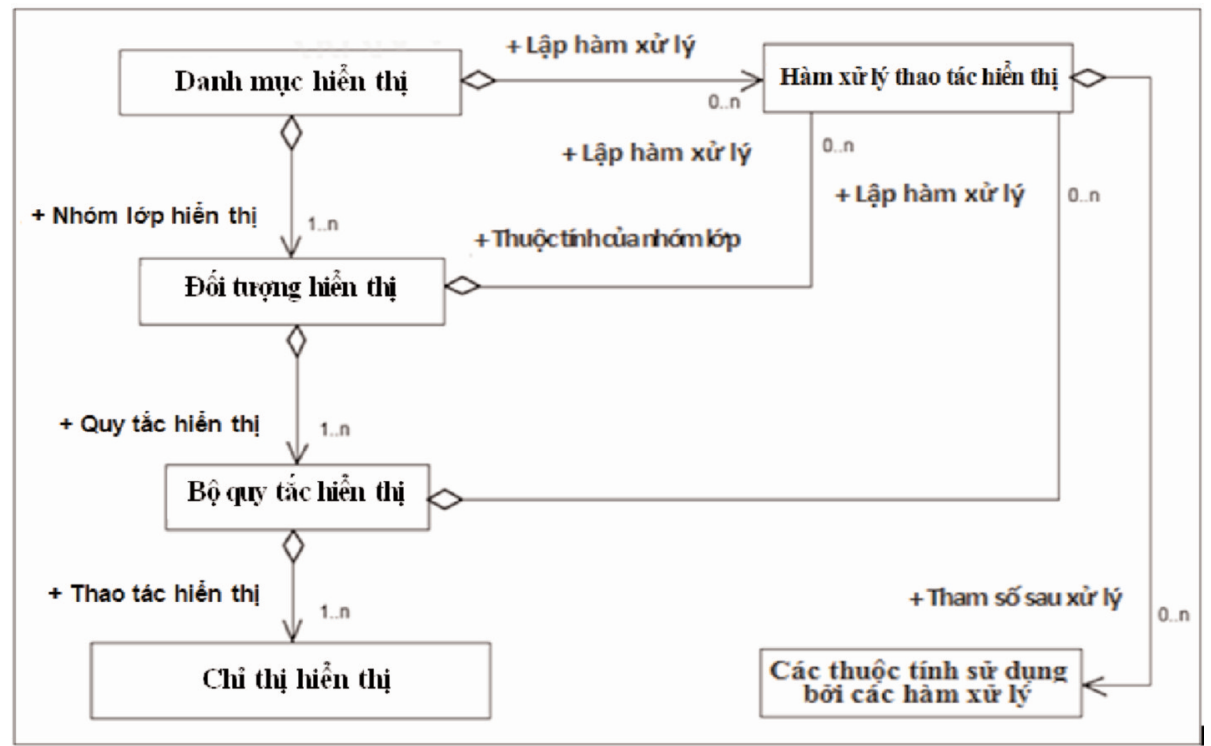

Hình 4: Mô hình khái niệm Danh mục hiển thị 
chú khi không đủ diện tích để xê dịch tránh chồng đè; Ghi chú ưu tiên đặt gần đối tượng và theo thứ tự 8 vị trí đặt xung quanh đối tượng; Ưu tiên hiển thị thứ tự đối tượng, lớp phục vụ chế in.

- Nguyên tắc hiển thị ký hiệu tại những vị trí đặc biệt quy định hiển thị đốt đặc tại vị trí góc ngoặt hoặc chỗ giao nhau của hai ký hiệu đường nét đứt, hiển thị thông tuyến giữa các cấp đường.

- Nguyên tắc hiển thị thông tin ghi chú kết hợp ký hiệu: nguyên tắc này định nghĩa cho các đối tượng ghi chú tính chất của các đối tượng địa lý như hướng hiển thị ký hiệu, rải ký tự ghi chú theo các đối tượng...

- Nguyên tắc tạo kỹ xảo mặt nạ: dùng để định nghĩa cho các đối tượng sử dụng để che một phần đối tượng tại các vị trí xảy ra xung đột không gian với các ký hiệu khác, nhằm đảm bảo khả năng dễ đọc thông tin trên bản đồ.

Đối với các bản đồ điện tử, các nguyên tắc trên vẫn luôn đúng, tuy nhiên các tham số về ưu tiên hiển thị không tính bằng theo công thức $0.2 \times \mathrm{M}$, mà cần được linh hoạt (nới rộng tham số) sao cho đảm bảo khả năng dễ đọc thông tin trên màn hình.

Việc ứng dụng các nguyên tắc đề xuất trên để xây dựng các quy tắc hiển thị tự động cho mỗi đối tượng nội dung bản đồ (Rule) có thể coi là các giải pháp thành phần cho việc hiển thị tự động ở mức đối tượng. Tập hợp tất cả các quy tắc hiển thị trên được gọi là bộ Luật hiển thị, trong đó các ký hiệu số (dạng điểm, đường và vùng) được gắn với các yêu cầu kỹ thuật hiển bản đồ.
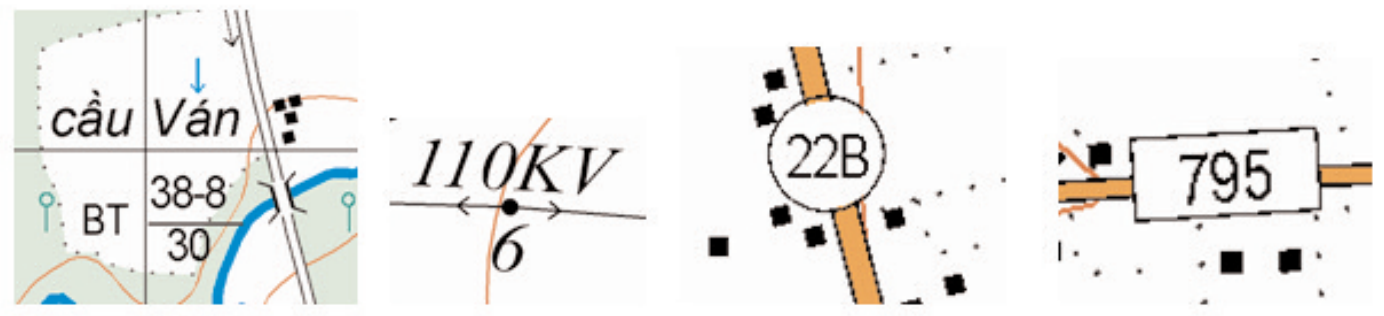

Hinh 5: Minh họa hiển thị tụ động đối tượng địa lý theo quy tắc thiết kế trước

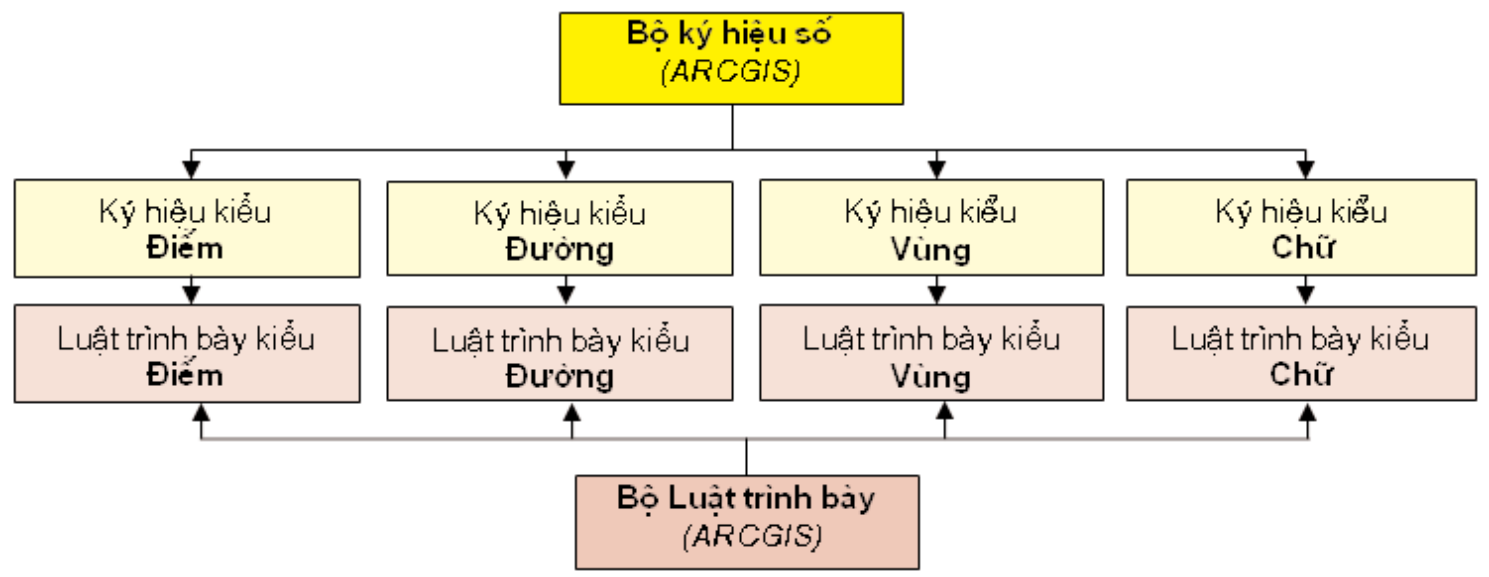

Hình 6: Mô hình thiết kế bộ Luật trình bày 
2.2.3. Nguyên tắc nhận dạng đối tượng bằng mã hóa

Để nhận dạng một đối tượng bản đồ bất kỳ ở các tỷ lệ có mức độ khái quát hóa khác nhau, cần xác lập một hệ thống mã nhận dạng. Chiến lược phát triển trong mã hóa hệ thống cần tính đến các bài toán:

- Đồng bộ hóa thông tin các thực thể địa lý giữa các tỷ lệ song hành với đồng bộ hóa thông tin hiển thị các yếu tố nội dung bản đồ giữa các tỷ lệ.

- Quản lý hiển thị các thông tin địa lý theo cơ chế phiên bản.

Đề xuất sử dụng nguyên tắc phát triển bộ mã định danh cho đối tượng nội dung bản gồm 32 ký tự ngẫu nhiên, là sự tổ hợp giữa chữ cái và số. Cơ chế phiên bản được kiểm soát cũng bằng hệ mã bao gồm 32 ký tự (dạng số) nhưng được đánh số từ 1 đến hết theo sự gia tăng của các phiên bản.

Việc áp dụng bộ mã cho mỗi chủ đề hiển thị là gắn chủ đề với một mã định danh hiển thị duy nhất (Specification-ID) và thông tin quản lý theo cơ chế phiên bản (ClassVersion-ID) gồm 32 ký tự ngẫu nhiên, nhằm mục đích nhận dạng quy tắc hiển thị trong môi trường đa hiển thị từ cùng một CSDL dùng chung và theo các phiên bản cập nhật theo các thời điểm khác nhau. (Xem hinh 7)

Ngoài các trường thông tin chung, mỗi quy tắc trình bày lại được ràng buộc mối quan hệ giữa mã định danh hiển thị (Specification-ID) với mã định danh của đối tượng địa lý (GFID), nhằm đảm bảo tính duy nhất của mỗi quy tắc khi thiết kế trong hệ thống. (Xem hinh 8)

\subsubsection{Nguyên tắc thiết kế}

Bộ quy tắc hiển thị tự động là tập hợp các Luật gắn với từng đối tượng nội dung bản đồ, trong các ngữ cảnh hiển thị nội dung phù hợp với đặc điểm địa lý và đáp ứng cho mục đích sử dụng, cụ thể được tổ chức như sau:

- Tỷ lệ: bao gồm tất cả các tỷ lệ cần hiển thị.

- Chủ đề: tập hợp tất cả các chủ đề nội dung của bản đồ (ví dụ: bản đồ địa hình quân sự gồm 7 nhóm lớp: Điểm khống chế trắc địa, Địa hình, Thủy hệ, Giao thông, Dân cư, Địa giới hành chính và ranh giới, Thực vật).

\begin{tabular}{|c|c|c|c|c|}
\hline OBJECTID & GFID & Name & Description & ClassVersionld \\
\hline 1 & (598A219E-644C-480F-A312-5C7F9F910156) & 50k.eiếm khóng ché trăc địa & Trình bày Điếm khống chế trắc địa & $(00000000-0000 \cdot 0000-0000 \cdot 000000000001)$ \\
\hline 2 & (7E5342A4-5183-439B-A554-2fED466974BS) & 50K.थja himh & Trình bày D̈ja hình & $(00000000 \cdot 0000 \cdot 0000 \cdot 0000 \cdot 000000000001)$ \\
\hline 3 & (A20C7263-DA07-475E-8AF9-FBC23220EEA0) & 50K-Thưy hê. & Trình bày Thüy hêt & $\{00000000 \cdot 0000 \cdot 0000 \cdot 0000 \cdot 000000000001]$ \\
\hline 4 & (37096012-E230-4451-B558-943063B666CE) & 50K.Giao Thông & Trinh bày Giao thông & $(00000000 \cdot 0000 \cdot 0000 \cdot 0000 \cdot 000000000001)$ \\
\hline 5 & (B0439BBB-0945.4581-9642-65E364281282) & 50K. OÂn cu & Trình bày Dân cư và ce sả hạ tăng & $(00000000 \cdot 0000 \cdot 0000 \cdot 0000 \cdot 000000000001)$ \\
\hline 6 & (D8E40038-274D-4B1E-8209-3FD9285C8CDO) & 50k-Ẹja giái hành chính và rạnh gới & Trình bày Địa gới hành chinh và ranh giới & $(00000000 \cdot 0000-0000 \cdot 0000-000000000001)$ \\
\hline 7 & (223DAEBC-C6AE-4597-959E-DE3271DASB57] & 50K-Thực rọ̆t & Trình bày Thực vột: & {$[00000000-0000-0000-0000-000000000001]$} \\
\hline
\end{tabular}

Hình 7: Minh họa quản lý mã định danh và cơ chế phiên bản của Bộ quy tắc hiển thị

\begin{tabular}{|c|c|c|c|c|c|}
\hline OBJECTID & GFID & Name & Layer & Idfield & Specificationld \\
\hline 3 & $(9698 C 742 \cdot 2826 \cdot 4941 \cdot B 1 C A \cdot E E 78171423 \mathrm{Cg})$ & DiemGocDoDac & DiemGocDoDac & DiemGocDoDac iD & (598A219E-644C-480F-A312-5C7F9F910156) \\
\hline 4 & (873F3F3F-AFF62-4EAE-9138-FOAEFBFBB1CO\}) & DiemDoDacCoso & Diem DoDacCoso & DiemDoDacCoso 10 & (598A219E-6A4C-4BOF-A312-5C7F9F910156) \\
\hline 8 & (CA67BS4A-4A-40-4182-ASD7-E9988F6A2BE9) & DiemDoCso & Diem DoCao & Rulelo & (TRS3:42A-4-51B3-4398-AS54-2FED 4669748S) \\
\hline 9 & (605208BE-DCF5-4009-A599-2C51C96C5198) & DuongBinhDo & Duongsinhoo & DuongBinhDo Rep ID & (TES3-42A4-51B3-4398-A554-2FED 46697485) \\
\hline 10 & (AFDASF25-4455-4EE3-BSF6.ADSE 4765E095) & DiemDosau & DiemDosau & DiemDosau Rep ID & (TES3:42A4-51B3-4398-A554-2FED46697485) \\
\hline
\end{tabular}

Hình 8: Minh họa quản lý mã định danh địa lý và mã định danh hiển thị của quy tắc hiển thi 
- Nhóm lớp, lớp thông tin: bao gồm quy tắc hiển thị cho mỗi đối tượng bản đồ hoặc nhóm đối tượng bản đồ.

- Quy tắc hiển thị: bao gồm định nghĩa tên quy tắc, hàm truy vấn thông tin được xử lý hiển thị, các tham số xử lý, thuộc tính lựa chọn để xử lý, đối tượng xử lý, lớp/nhóm lớp thông tin quản lý đối tượng được lựa chọn xử lý, chủ đề hiển thị, tên luật hiển thị (ký hiệu số gắn với quy tắc hiển thị), thứ tự xử lý tự động trong chủ đề.

\subsubsection{Quy trình thành lập Bộ quy tắc hiển} thị tự động

Quy trình xây dựng Bộ quy tắc hiển thị bản đồ tự động gồm các bước (xem hình 7):

- Xác lập bảng ánh xạ đối tượng địa lý và bản đồ: chỉ ra quan hệ giữa đối tượng địa lý trong CSDL tương ứng là đối tượng bản đồ nào hiển thị trong nội dung bản đồ.

- Tổ chức chủ đề hiển thị: chủ đề hiển thị bản đồ địa hình tuân theo cách phân loại chủ đề nội dung của chuyên ngành.

- Tổ chức nhóm lớp thông tin hiển thị: lấy theo tên của đối tượng tượng địa lý chứa các đối tượng nội dung bản đồ để dễ quản lý và truy vấn thông tin.

- Lập hàm truy vấn đối tượng hiển thị: căn cứ vào bảng ánh xạ, tiêu chí hiển thị đối tượng bản đồ và các thuật toán truy vấn theo ngôn ngữ Visual Basic để lập các hàm lựa chọn đối tượng bản đồ từ cấu trúc CSDL nền địa lý.

- Xác lập luật trình bày đối tượng: là bước gán luật tương ứng cho đối tượng bản đồ. (Xem hình 9)

\subsubsection{Mẫu trình bày}

Mẫu trình bày đại diện cho cách thức tổ chức thông tin nội dung một loại bản đồ nhất định. Nguyên tắc tổ chức các lớp thông tin và thứ tự hiển thị của các đối tượng như sau: 1) Các nhóm lớp được đặt tên tương tự như bản đồ truyền thống (để gần gũi với thói quen sử dụng truyền thống). 2) Chia nội dung chính của bản đồ thành 4 nhóm lớn theo dạng dữ liệu: Đối tượng dạng điểm, Đối tượng dạng đường, Đối tượng dạng vùng và Đối tượng dạng ghi chú để đảm bảo kỹ thuật hiển thị theo nguyên tắc đối tượng điểm ở trên cùng, rồi đến đối tượng đường, đối tượng vùng ở dưới cùng. 3) Tất cả các đối tượng trình bày khung và ngoài khung bản đồ quản lý trong nhóm "Khung và trình bày ngoài khung". Nhóm này sẽ được sử dụng chung cho các bản đồ cùng kiểu, trong đó có xét đến sự chỉnh sửa, bổ sung nhưng thông tin đặc trưng của từng bản đồ (ví dụ bản đồ địa hình quân sự cần trình bày sơ đồ địa giới, bảng chắp, lược đồ dáng đất... đặc trưng riêng của từng mảnh).

Xác lập bảng ánh xạ đối tượng địa lý và bản đồ

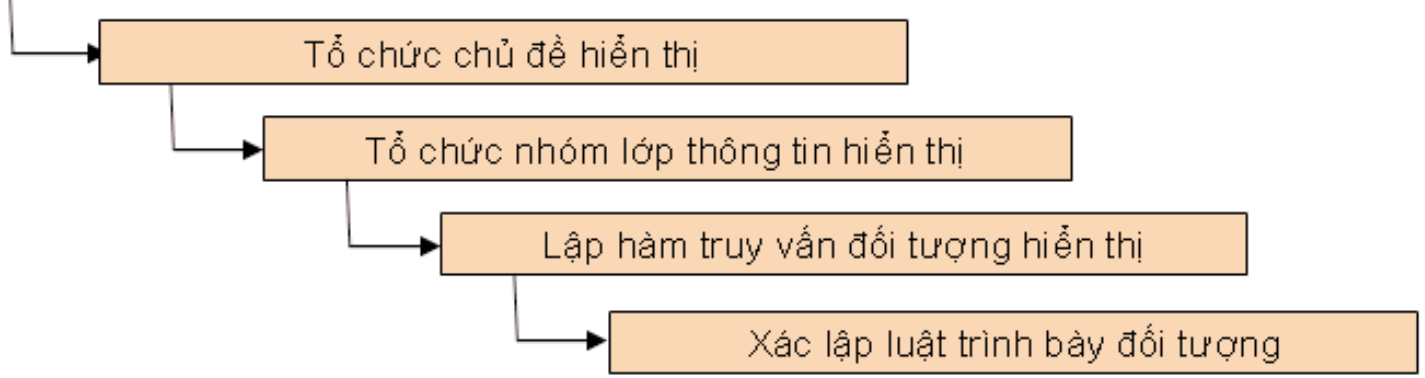

Hình 9: Sơ đồ quy trình xây dựng Bộ quy tắc hiển thị tự động 
2.3. Thử nghiệm xây dựng Bộ quy tắc hiển thị cho bản đồ địa hình quân sự tỷ lệ 1:10.000, 1:25.000 và 1:50.000

Việc thử nghiệm tiến hành cho các tỷ lệ từ 1:10.000 đến 1:50.000, là những tỷ lệ thuộc nhóm trung bình, phức tạp hơn trong việc hiển thị so với các tỷ lệ còn lại trong dãy tỷ lệ bản đồ địa hình quân sự. Nhóm lớp quân sự không hiển thị trên bản đồ in giấy nên không thiết kế luật trình bày trong Bộ quy tắc. (Xem bảng 1)

Số lượng luật của mỗi nhóm đối tượng thuộc các tỷ lệ khác nhau do quy định kỹ thuật biên tập bản đồ thuộc mỗi tỷ lệ khác nhau. Đặc biệt CSDL tỷ lệ 1:50.000 được làm từ bản đồ có trước nên có thêm lớp mã trình bày bản đồ, vì vậy số lượng luật hiển thị không theo quy luật tăng/giảm như đối với tỷ lệ $1: 10.000$ và 1:25.000. (Xem hình 10)

Bảng 1: Thống kê các quy tắc hiển thị bản đồ địa hình quan sự theo tỷ lệ

\begin{tabular}{|c|l|c|c|c|}
\hline STT & \multicolumn{1}{|c|}{ Nội dung } & $\mathbf{1 : 1 0 . 0 0 0}$ & $\mathbf{1 : 2 5 . 0 0 0}$ & $\mathbf{1 : 5 0 . 0 0 0}$ \\
\hline 1 & Cơ sở đo đạc & 3 & 3 & 3 \\
\hline 2 & Địa hình & 17 & 23 & 23 \\
\hline 3 & Thủy hệ & 45 & 49 & 62 \\
\hline 4 & Giao thông & 59 & 65 & 76 \\
\hline 5 & Dân cư, cơ sở hạ tầng & 69 & 56 & 31 \\
\hline 6 & Biên giới, địa giới & 9 & 3 & 4 \\
\hline 7 & Phủ bề mặt & 55 & 24 & 15 \\
\hline & Tổng số & $\mathbf{2 5 7}$ & $\mathbf{2 2 3}$ & $\mathbf{2 3 7}$ \\
\hline
\end{tabular}

D:'Thu nghiem he thongitTrinh bay he thong ban do dia hinhi,HeThongTrinhBay_PL.gdt

\begin{tabular}{|c|c|}
\hline Specification & Description \\
\hline 10K.Điềm khống chế trắc địa & Trình bà̀y Điềm khống chế trắc địa \\
\hline 10K.Địa hình & Trình bày Eịa hình \\
\hline 10K-Thùy hệ & Trình bày Thùy hệ \\
\hline 10K-Giao thông & Trình bày Giao thông \\
\hline 10K-Dân cul & Trình bày Dần cu và cơ sở hậ tầng \\
\hline 10K.Địa giơi hành chính wà ranh giôi & Trình bày Địa giôii hành chính và ranh giôi \\
\hline 10K-Thục wật & Trình bày Thục vật \\
\hline 25K Điền không chể trắc địa & Trình bày Eliềm khö̉ng chễ trắc địa \\
\hline 25K.Eịa hinh & Trình bày Elịa hình \\
\hline 25K-Thủy hệ & Trình bày Thủy hệ \\
\hline 25K-Gilao Thông & Trình bày Giao thông \\
\hline 25K.Dăn cul & Trình bày Dằn cu và cơ sở hạ tầng \\
\hline 25K. Eịa giỡi hành chính wà ranh giỡi & Trình bày Elịa giôii hành chính và ranh giồi \\
\hline 25K-Thục vật & Trình bày Thục vật \\
\hline 50K Điển khống chế trắc địa & Trình bày Điềm khớng chễ trắc địa \\
\hline 50K-Eịa hình & Trình bày Eịa hình \\
\hline 50K-Thüy hệ & Trình bày Thüy hệ \\
\hline 50K-Giao Thông & Trình bày Giao thông \\
\hline 50K-Dần cu & Trình bày Dần cu và cơ sỏ hạ tầng \\
\hline 50k-Địa giői hành chính và ranh giởi & Trình bày Địa giơii hành chính và ranh giôi \\
\hline 50K-Thục wật & Trình bày Thục vật \\
\hline
\end{tabular}

Hình 10: Minh họa Bộ quy tắc hiển thị các tỷ lệ 1:10.000, 1:25.000 và 1:50.000 


\section{Kết luận}

Các quy tắc hiển thị bản đồ kết hợp với tiêu chí lấy bỏ các yếu tố nội dung bản đồ từ thông tin địa lý có trong CSDL nền địa lý quân sự, có thể được thiết kế thành các Bộ quy tắc hiển thị bản đồ phù hợp với mục đích sử dụng và phương pháp khai thác thông tin (bản đồ số phục vụ in bản đồ giấy hoặc bản đồ điện tử).

Bộ quy tắc hiển thị góp phần nâng cao khả năng tự động hóa trong thành lập bản đồ quân sự từ CSDL nền địa lý quân sự.

Các nguyên tắc thiết kế Bộ quy tắc hiển thị bản đồ địa hình quân sự như trên, không chỉ đáp ứng được yêu cầu về đa hiển thị từ một CSDL dùng chung, mà nó hoàn toàn có thể sử dụng để phát triển lý thuyết và thử nghiệm thiết kế cho các loại bản đồ phục vụ cho các mục đích khác nhau. $O$

\section{Tài liệu tham khảo}

[1]. Bộ Tài nguyên và Môi trường (2012), Tiêu chuẩn quốc gia QCVN 42:2012/BTNMT Quy chuẩn kỹ thuật Quốc gia về chuẩn thông tin địa lý cơ sở, Hà Nội.

[2]. Bộ Tổng Tham mưu (2010), Địa hình quân sự, Hà Nội.
[3]. Bộ Tổng Tham mưu (2011), Tiêu chuẩn quốc gia TCVNQS 1488:2011, Hà Nội.

[4]. Bộ Tổng Tham mưu (2011), Tiêu chuẩn quốc gia TCVNQS 1489:2011, Hà Nội.

[5]. Đỗ Xuân Lôi (2008), Cấu trúc dũ liệu và giải thuật, Nhà xuất bản Đại học Quốc gia, Hà Nội.

[6]. Barbara P. Buttenfield, Torrin Hultgren (2009), Managing Multiple Representations of "Base Carto" Features:A Data Modeling Approach, Department of Geography CB-260, University of Colorado, Boulder, CO 80309-0260.

[7]. Molenaar, M. (1998), An Intrudution to the Theory of Spatial Object Modelling, Research Monograph in GIS Series, Taylor \& Francis, London.

[8]. Sheng Zhou, Christopher B. Jones (2009), A Multi-Representation Spatial Data Model, Department of Computer Science , Cardiff University , Cardiff, CF24 3XF, United Kingdom.

[9]. J.E. Stoter (2005), Generalisation within NMA.S in the 21st Century, ITC, Enschede, the Netherlands. O

\section{Summary}

Research findings to build the display rules for topographic map from the military geographic database

MSc. Nguyen Thi Lan Phuong

\section{Army Catographic Department}

The article presents research findings to build the display rules for topographic map from the military geographic database based on GIS and Digital Mapping technology. The display rules are solution to improve the automation mapping from the database. The study results can be applied to build the display rules different maps corresponding to each specific purpose. $O$

Ngày nhận bài: 15/11/2013. 